\title{
Tissue cross-reactivity studies of CPGJ701 in humans, cynomolgus monkeys and Sprague-Dawley rats and correlation analysis with in vivo toxicity
}

\author{
Zhe Qu ${ }^{1 \#}$, Jianjun Lyu ${ }^{1 \#}$, Yue Liu ${ }^{2}$, Xin Wang ${ }^{1}, Z_{\text {hi }}$ Lin $^{1}$, Yanwei Yang ${ }^{1}$, Di Zhang ${ }^{1}$, Xingchao Geng ${ }^{1}$, \\ Bo $\mathrm{Li}^{3}$
}

${ }^{1}$ Beijing Key Laboratory for Safety Evaluation of Drugs, National Center for Safety Evaluation of Drugs, National Institutes for Food and Drug Control, Beijing 100176, China; ${ }^{2}$ Sunshine Guojian Pharmaceuticals (Shanghai) Co., Ltd., Shanghai 201203, China; ${ }^{3}$ National Institutes for Food and Drug Control, Beijing 102629, China

Contributions: (I) Conception and design: Z Qu, Y Liu; (II) Administrative support: B Li, X Geng; (III) Provision of study materials or patients: X Geng, B Li; (IV) Collection and assembly of data: Z Qu, J Lyu, Y Liu, Z Lin, Y Yang, D Zhang; (V) Data analysis and interpretation: Z Qu, J Lyu, Y Liu, X Wang; (VI) Manuscript writing: All authors; (VII) Final approval of manuscript: All authors.

\#These authors contributed equally to this work.

Correspondence to: Bo Li, PhD. Professor, National Institutes for Food and Drug Control, Beijing, 102629, China. Email: libo@nifdc.org.cn.

Background: CPGJ701 is a recombinant humanized anti-human epidermal growth factor receptor-2 (HER2) monoclonal antibody-derivative of the cytotoxic agent maytansine (DM1) conjugate for the treatment of HER2-positive metastatic breast cancer. Tissue cross-reactivity (TCR) studies of CPGJ701 in a complete panel of normal human, cynomolgus monkey and Sprague-Dawley were performed to provide evidence for selecting animal species for use in preclinical toxicity studies and predicting primary target organs and clinical adverse drug reactions (ADRs).

Methods: TCR studies were carried out to evaluate the distribution of reactivity and the TCR of CPGJ701 in paraffin sections of 32 tissues and/or organs (such as the heart, lung, liver, and kidney) from at least three unrelated normal human, cynomolgus monkey and Sprague-Dawley rat donors. The TCR of CPGJ701was detected by one-step immunohistochemical method using $50 \mu \mathrm{g} / \mathrm{mL}$ biotin-labeled CPGJ701 as the primary antibody. Moreover, a negative biotin-labeled human IgG control group, a blank phosphate-buffered saline (PBS) control group, and a positive human breast cancer tissue control group were also used to exclude false positive and false negative results. The specific positive binding and distribution of reactivity of CPGJ701 were detected in the human breast cancer tissue and 32 tissues from normal humans, cynomolgus monkeys and Sprague-Dawley rats under a microscope.

Results: The TCR of CPGJ701 in humans and cynomolgus monkeys was highly consistent but showed some differences compared to the TCR of CPGJ701 in Sprague-Dawley rats. The binding of CPGJ701 to target tissues, such as the liver, adrenal gland, thyroid, fallopian tube, spinal cord and skin, was observed in humans and cynomolgus monkeys but not in Sprague-Dawley rats. Specific binding to the placenta was only found in Sprague-Dawley rats. The cell types to which CPGJ701 specifically bound, including epithelial cells, cardiomyocytes and nerve cells, were identical in humans, cynomolgus monkeys and rats.

Conclusions: The TCR of CPGJ701 was in accord with the targeting characteristics of the humanized anti-HER2 monoclonal antibody. The consistency of CPGJ701 binding to human and cynomolgus monkey tissues indicated that the cynomolgus monkey is a relevant animal species for evaluating the preclinical safety of CPGJ701. The targeting (binding site) of CPGJ701 in Sprague-Dawley rats indicated that it is also a useful animal species for evaluating antibody-dependent toxicity and non-antibody-dependent toxicity. In conclusion, these TCR studies of CPGJ701 could provide information for selecting relevant animal species for nonclinical studies and predicting clinical ADRs. 
Keywords: Antibody-drug conjugate (ADC); human tissue; cynomolgus monkey tissue; Sprague-Dawley rat tissue; tissue cross-reactivity (TCR)

Submitted Dec 04, 2019. Accepted for publication Feb 05, 2020.

doi: $10.21037 /$ atm.2020.02.106

View this article at: http://dx.doi.org/10.21037/atm.2020.02.106

\section{Introduction}

Recombinant humanized anti-human epidermal growth factor receptor-2 (HER2) monoclonal antibody-derivative of the cytotoxic agent maytansine (DM1) conjugate (CPGJ701) is an antibody-drug conjugate (ADC) for the treatment of HER2-positive metastatic breast cancer (1). CPGJ701 consists of an antibody, a chemical linker, and a DM1, the cytotoxic tubulin inhibitor DM1 is conjugated to a targeted HER2 antibody via a chemical linker $(2,3)$. The mechanism of action is that the antibody component of the ADC is targeted to bind to the extracellular HER2 domain on the surface of tumor cells and enter the tumor cells by endocytosis. The ADC is enzymatically lysed in lysosomes, and releases the toxins DM1, which disrupts the stability of the intracellular microtubules of tumor cells, leading to tumor cell cycle arrest and apoptosis (4). Since DM1 is selectively released into tumor cells and has a lower killing effect on normal cells, CPGJ701 should be more targeted and safer than DM1 alone.

However, although the monoclonal antibody component of the $\mathrm{ADC}$ enhances the targeting of cytotoxic DM1 and theoretically reduces its toxic effects on normal tissues, ADCs have shown a series of side effects in clinical and nonclinical studies (5). There a variety of mechanisms of toxicity. First, targeted nontumor toxicity is caused by the extensive expression of the HER2 antigen in normal tissues. The HER2 antigen is the tumor-targeting binding site of the ADC, and its distribution in vivo seems to determine the target of ADC toxicity. the expression of HER2 in normal tissues such as the lung and gastrointestinal tract may not only reduce the delivery of ADCs to tumors, but also more importantly cause on-target off-tumor toxicity. Although the expression of the HER2 antigen on tumors is higher than that on normal tissues, clinical studies have demonstrated that the success of ADCs depends on the targeting technology (6). Second, the cytotoxic drug DM1 and its metabolites cause off-target toxicity to surrounding cells, i.e., inhibition of cell mitosis and cell cycle arrest, due to separation from the monoclonal antibody component after internalization $(7,8)$. Clinical and nonclinical studies of DM1 have shown that the main target organs of this toxic effect include the liver, bone marrow, lymphoid organs, gastrointestinal tract and central/peripheral nervous system.

Based on the structural characteristics and mechanisms of toxicity of ADCs, it is necessary to evaluate the antibody as a component of the biological product, the toxicity of the small molecule drug and the nonclinical safety of the ADC (9). The International Council for Harmonization (ICH) S6 guideline stipulates that tissue cross-reactivity (TCR) immunohistochemistry (IHC) studies be performed on investigational new antibody-based drugs before the submission of clinical trial applications for initial dosing in human subjects (10). The purpose of TCR studies is to predict potential target organs of toxicity based on the binding of antibodies to normal tissues (11). Immunohistochemical methods can be used to study the on-target and off-target binding of antibody drugs to human tissues in vitro as well as differences in tissue binding between nonclinical species. TCR studies of trastuzumab and ADCs have shown that the process of conjugating the small molecule drug to the antibody affects the targeted binding of the antibody. In this study, the specific binding of CPGJ701 to 32 normal human tissues, cynomolgus tissues and Sprague-Dawley rat tissues was detected by IHC to evaluate the on-target effect and possible off-target toxicity of CPGJ701: this will provide a reference for selecting animal species for nonclinical studies and predicting clinical adverse drug reactions (ADRs).

\section{Methods}

\section{Tissue sources}

Specific positive expression of CPGJ701 in paraffin sections of a complete panel of normal human, cynomolgus monkey and Sprague-Dawley rat tissues from the three donors was assessed by a one-step immunohistochemical method. The human tissues were autopsy samples from a hospital or human tissue chips purchased from Beijing Long Maida 
Technology Co., Ltd. Cynomolgus monkey and SpragueDawley rat tissues were collected during necropsy at the National Center for Safety Evaluation of Drugs. Thirtytwo tissues, including tissues from the heart, the lung, the liver, the spleen, the kidney, the ureter, the stomach, the pituitary, the adrenal gland, the thyroid, the parathyroid gland, the bladder, the cerebellum, the cerebral cortex, the colon, the eyes, the lymph nodes, the mammary gland, the pancreas, the prostate, the skin, striated muscle, the testes, the thymus, the uterus, the ovaries, the fallopian tube, bone marrow, the placenta, the blood vessel endothelium, blood cells and the spinal cord (12), were collected from each donor, with male and female reproductive organs being collected from three unrelated donors.

By testing the expression of $\beta 2$ microglobulin in paraffinembedded tissues (expressed in epithelial cells, vascular endothelial cells, blood cells, etc., but not in muscle tissue, brain tissue, etc.), we proved that human tissue antigens were well preserved. By comparing the expression of transferrin, neurofilament, etc., in frozen tissues and paraffin-embedded tissues from cynomolgus monkeys, it was proven that formalin-fixed tissue antigens were not lost and that antigen expression was not inhibited.

\section{IHC procedure}

Rehydrated paraffin sections were immersed in $3 \%$ hydrogen peroxide $\left(\mathrm{H}_{2} \mathrm{O}_{2}\right)$ for 10 min to block endogenous peroxidase activity and then immersed and heated in citrate buffer ( $\mathrm{pH}$ 6.0) for $10 \mathrm{~min}$ for antigen retrieval. To eliminate nonspecific staining and block endogenous biotin, tissues were incubated in normal sheep serum blocking solution for $50 \mathrm{~min}$ at $37^{\circ} \mathrm{C}$ and in avidin and biotin solutions for $15 \mathrm{~min}$ at room temperature. The sections were incubated with biotinylated CPGJ701 (batch no.: B0003B01: original concentration of $2 \mathrm{mg} / \mathrm{mL}$ BioCPGJ701; Beijing Boaosen Biotechnology Co., Ltd.) as a primary antibody at $4{ }^{\circ} \mathrm{C}$ overnight followed by $1: 200$ diluted horseradish peroxidase-labeled streptavidin (SA/ HRP) (batch no.: ZB-2404; Beijing Zhongshang Golden Bridge Biotechnology Co., Ltd.) before diaminobenzidine (DAB) staining. Then, the sections were counterstained with hematoxylin, dehydrated, cleared and coverslipped, and the results were observed under a microscope.

\section{Experimental design and grading criteria}

The experimental design of the TCR study of CPGJ701 in normal human, cynomolgus monkey and Sprague-Dawley rat tissues included a $50 \mu \mathrm{g} / \mathrm{mL}$ Bio-CPGJ701 test article group, a blank phosphate-buffered saline (PBS) control group, and a $50 \mu \mathrm{g} / \mathrm{mL}$ Bio-IgG (batch no.: 20160711; Beijing Suo Labao Technology Co., Ltd.) negative control group to identify nonspecific reactions and false positive results (Table 1). In addition, human breast cancer tissue was used as HER2 protein positive control tissue to ensure the accuracy of the test procedures and identify false negative results. Kadcyla (batch no.: B0003B01) was added as an isotype control drug for comparisons with the TCR of CPGJ701.

No staining (-) was considered a real negative result under the premise of the false negative result being excluded. Nonuniform staining was considered a false positive result. By comparing the staining intensity of uniformly stained tissue with human breast cancer tissue and taking into account the possible positive expression sites of HER2, the specific TCR of the tissues from the 3 donors was comprehensively evaluated by pathologists as weak staining $( \pm)$, mild staining $(1+)$, moderate staining $(2+)$ or strong staining $(3+)$ (Table 2).

\section{Results}

\section{Normal buman tissues}

The results showed that CPGJ701 specifically bound to the tumor cell membrane and cytoplasm in three unrelated human breast cancer tissues (Figure 1). In normal human tissues, positive expression of CPGJ701 was identified in the heart, liver, renal tubular epithelium, transitional epithelium of the ureter, gastric mucosa, glandular epithelium of the pituitary gland, adrenal cortex, thyroid, transitional epithelium of the bladder, cerebellum, cerebral cortex, retina, acinus of the mammary gland, pancreas, prostate, epidermis, testicular seminiferous tubules, endometrium, fallopian tube mucosa, and spinal cord and in alveolar epithelial cells (Figure 2, Table 3). Binding to the kidney, stomach, pituitary, adrenal gland, bladder, mammary gland, skin and testes was observed in 3 of 3 individuals. Positive staining was observed in the membrane and cytoplasm of epithelial cells, cardiomyocytes and nerve cells. The staining intensity in epithelial cells was greater than that in cardiomyocytes and nerve cells.

No positive expression was observed in the spleen, the thymus, the lymph nodes, the colon, striated muscle, the ovaries, bone marrow, the blood vessel endothelium, blood 
Table 1 Experimental design

\begin{tabular}{llll}
\hline Groups & Primary antibody & Staining & Test system \\
\hline Test article & Bio-CPGJ701 $(50 \mu \mathrm{g} / \mathrm{mL})$ & $\begin{array}{l}\text { SA/HRP (1:200) + DAB of all Human breast cancer tissue; three panels of human/ } \\
\text { groups }\end{array}$ & $\begin{array}{l}\text { cynomolgus monkey/Sprague-Dawley rat tissues } \\
\text { Negative control }\end{array}$ \\
Blank control & PBS & & \\
\hline
\end{tabular}

SA/HRP, horseradish peroxidase-labeled streptavidin; DAB, diaminobenzidine; PBS, phosphate-buffered saline.

Table 2 Grading criteria for immunohistochemical staining

\begin{tabular}{ll}
\hline Staining intensity & Grade (symbols) \\
\hline No staining & Negative staining $(-)$ \\
No clear or non-uniform staining & Weak staining $( \pm)$ \\
Slight staining (light yellow or other colors) & Mild staining $(1+)$ \\
Moderate staining (brownish yellow or other colors) & Moderate staining $(2+)$ \\
Strong staining (brown or other colors) & Strong staining $(3+)$ \\
\hline
\end{tabular}
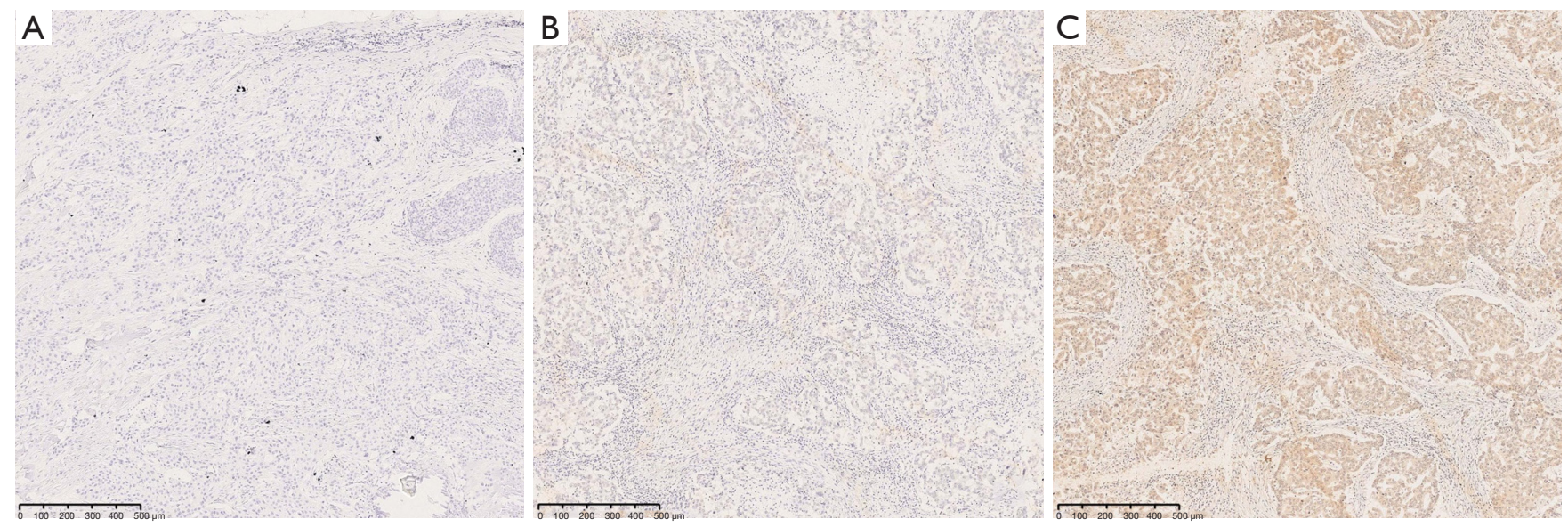

Figure 1 Immunohistochemical staining results of human breast cancer tissues. (A) Blank control group: negative staining; (B) negative control group: negative staining; (C) test article group: membrane and cytoplasm of human breast cancer cell showed mild (1+) positive staining.

cells, or the placenta. Bio-IgG and PBS resulted in no positive staining in human breast cancer tissue or the 32 normal human tissues.

\section{Normal cynomolgus monkey tissues}

In cynomolgus monkey tissues, positive binding of CPGJ701 was identified in the heart, the liver, the renal tubular epithelium, the transitional epithelium of the ureter, the gastric mucosa, the glandular epithelium of the pituitary, the adrenal cortex, the thyroid, the parathyroid gland, the transitional epithelium of the bladder, the cerebellum, the cerebral cortex, the retina, the acinus of the mammary gland, the islets of the pancreas, the epidermis, the spinal cord, the testicular seminiferous tubules, the endometrium, the ovarian follicles, the fallopian tube mucosa and interstitial mononuclear macrophages (Figure 3, Table 3). Binding to the liver, kidney, ureter, stomach, adrenal gland, parathyroid gland, bladder, mammary gland, islets of the pancreas, skin, testes and fallopian tubes was 

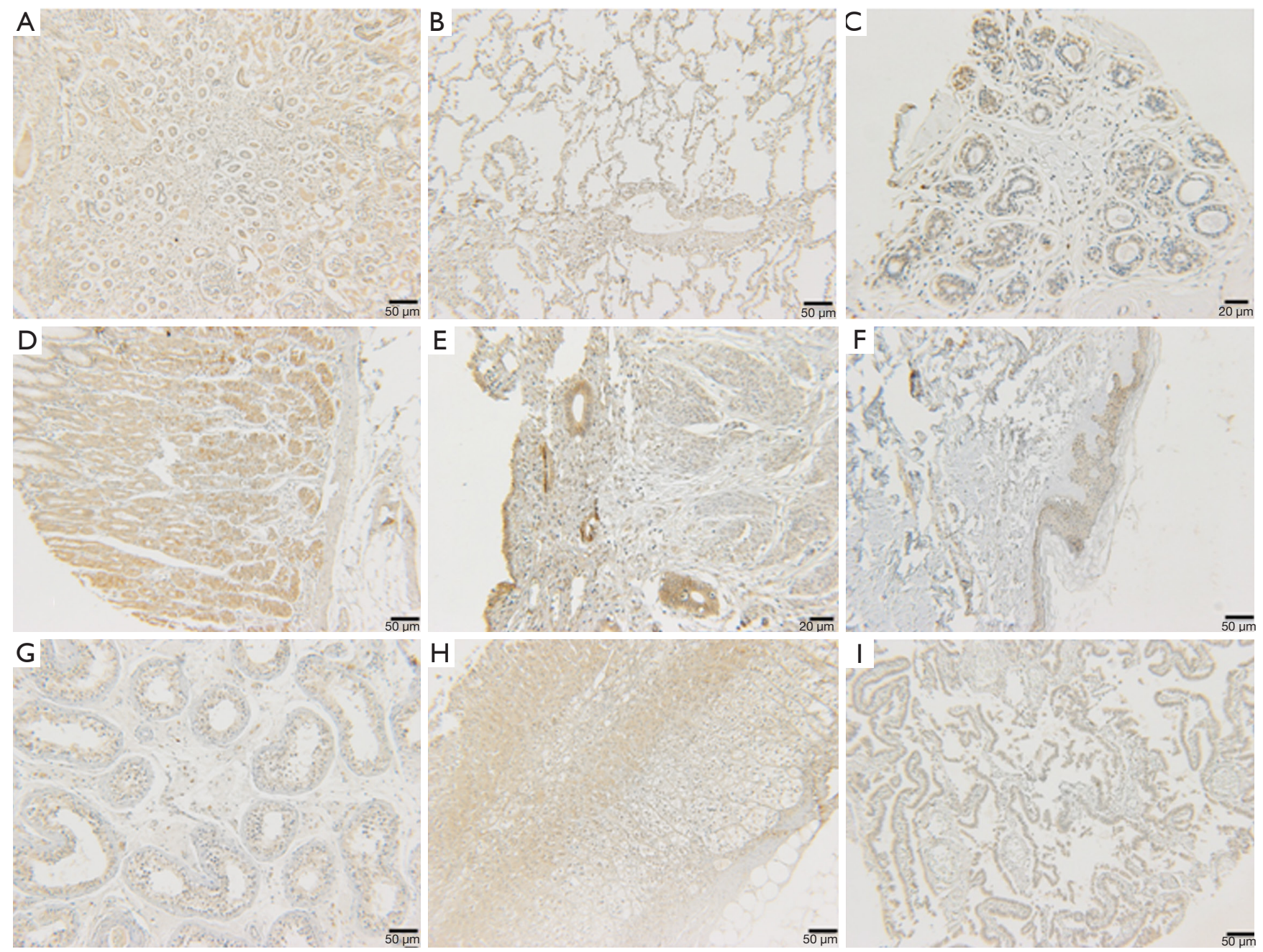

Figure 2 Specific binding of CPGJ701 with normal human tissues by IHC. (A) Moderate staining (2+) in renal proximal and distal tubular epithelial cells; (B) mild staining (1+) in alveolar epithelial cells; (C) mild staining (1+) in mammary gland epithelial cells; (D) moderate staining (2+) in gastric mucosal epithelial cells; (E) moderate staining (2+) in uterine endometrium and glandular epithelial cells; (F) moderate staining $(2+)$ in epidermis cells; $(G)$ moderate staining $(2+)$ in epithelial cells of testicular seminiferous tubules; $(\mathrm{H})$ moderate staining $(2+)$ in glandular epithelial cells of adrenal cortex; (I) mild staining (1+) in mucosal epithelial cells of fallopian tube. IHC, immunohistochemistry.

found in 3 of 3 individuals, and this binding was similar to or higher than that in the human tissues. The staining intensity in epithelial cells, cardiomyocytes and nerve cells of cynomolgus monkeys was similar to that in human tissues. Binding of CPGJ701 to lung and prostate epithelial cells was not observed for cynomolgus monkeys. Binding to interstitial mononuclear macrophages and ovarian follicles was only found in cynomolgus monkeys, and the staining intensity of interstitial mononuclear macrophages was higher than that of epithelial cells.

No positive expression was observed in the lung, the spleen, the thymus, the lymph nodes, the colon, striated muscle, the prostate, bone marrow, the blood vessels endothelium, blood cells, or the placenta. Bio-IgG and PBS resulted in no positive staining in the 32 normal cynomolgus monkey tissues.

\section{Normal Sprague-Dawley rat tissues}

In Sprague-Dawley rat tissues, positive binding of CPGJ701 was identified in the heart, the bronchial epithelium of the lung, the renal tubular epithelium, the 
Table 3 IHC results of CPGJ701 binding to tissues in normal humans, cynomolgus monkeys and Sprague-Dawley rats

\begin{tabular}{|c|c|c|c|}
\hline 32 tissues & \multicolumn{3}{|c|}{ Bio-CPGJ701 (50 ㅆg/mL) } \\
\hline Breast cancer & $1+(3 / 3)$ & / & / \\
\hline Heart & $1+(2 / 3)$ & $1+(2 / 3), \pm(1 / 3)$ & $1+(1 / 3), \pm(2 / 3)$ \\
\hline Lung & $1+(2 / 3)$ & - & $1+(1 / 3), \pm(1 / 3)$ \\
\hline Spleen & - & - & - \\
\hline Kidney & $2+(2 / 3), \pm(1 / 3)$ & $1+(2 / 3), \pm(1 / 3)$ & $1+(3 / 3)$ \\
\hline Ureter & $2+(1 / 3)$ & $1+(2 / 3), 2+(1 / 3)$ & $1+(2 / 3), \pm(1 / 3)$ \\
\hline Stomach & $1+(2 / 3), 2+(1 / 3)$ & $1+(1 / 3), 2+(2 / 3)$ & $1+(3 / 3)$ \\
\hline Thyroid & $1+(2 / 3), \pm(1 / 3)$ & $1+(1 / 3)$ & - \\
\hline Parathyroid & ND & $1+(2 / 3), 2+(1 / 3)$ & $1+(3 / 3)$ \\
\hline Bladder & $1+(2 / 3), 2+(1 / 3)$ & $1+(2 / 3), 2+(1 / 3)$ & $1+(2 / 3), \pm(1 / 3)$ \\
\hline Cerebellum & $1+(1 / 3), \pm(2 / 3)$ & $1+(1 / 3), \pm(1 / 3)$ & $1+(2 / 3), \pm(1 / 3)$ \\
\hline Cerebral cortex & $1+(2 / 3), \pm(1 / 3)$ & $1+(1 / 3)$ & $1+(2 / 3), \pm(1 / 3)$ \\
\hline Colon & - & $\pm(1 / 3)$ & $\pm(2 / 3)$ \\
\hline Retina & $1+(1 / 1)$ & $1+(2 / 3)$ & $1+(2 / 3)$ \\
\hline Lymph node & - & - & - \\
\hline Testes & $1+(2 / 3), 2+(1 / 3)$ & $1+(3 / 3)$ & $1+(2 / 3)$ \\
\hline Thymus & - & - & - \\
\hline Uterus & $1+(1 / 3), 2+(1 / 3)$ & $1+(1 / 3)$ & $1+(3 / 3)$ \\
\hline Ovaries & - & $1+(1 / 3)$ & - \\
\hline Fallopian tube & $1+(2 / 3)$ & $1+(2 / 3), \pm(1 / 3)$ & - \\
\hline Bone marrow & - & - & - \\
\hline Placenta & $\pm(1 / 3)$ & - & $1+(2 / 3), \pm(1 / 3)$ \\
\hline Endothelium & - & - & - \\
\hline Blood cells & - & - & - \\
\hline Spinal cord & $1+(1 / 3), \pm(2 / 3)$ & $1+(3 / 3)$ & - \\
\hline
\end{tabular}

- indicates negative; \pm indicates weak staining; $1+$ indicates mild staining; $2+$ indicates moderate staining; $3+$ indicates strong staining; ND indicates not done; / indicates no; (/) indicates the proportion of different grades of staining. IHC, immunohistochemistry. 

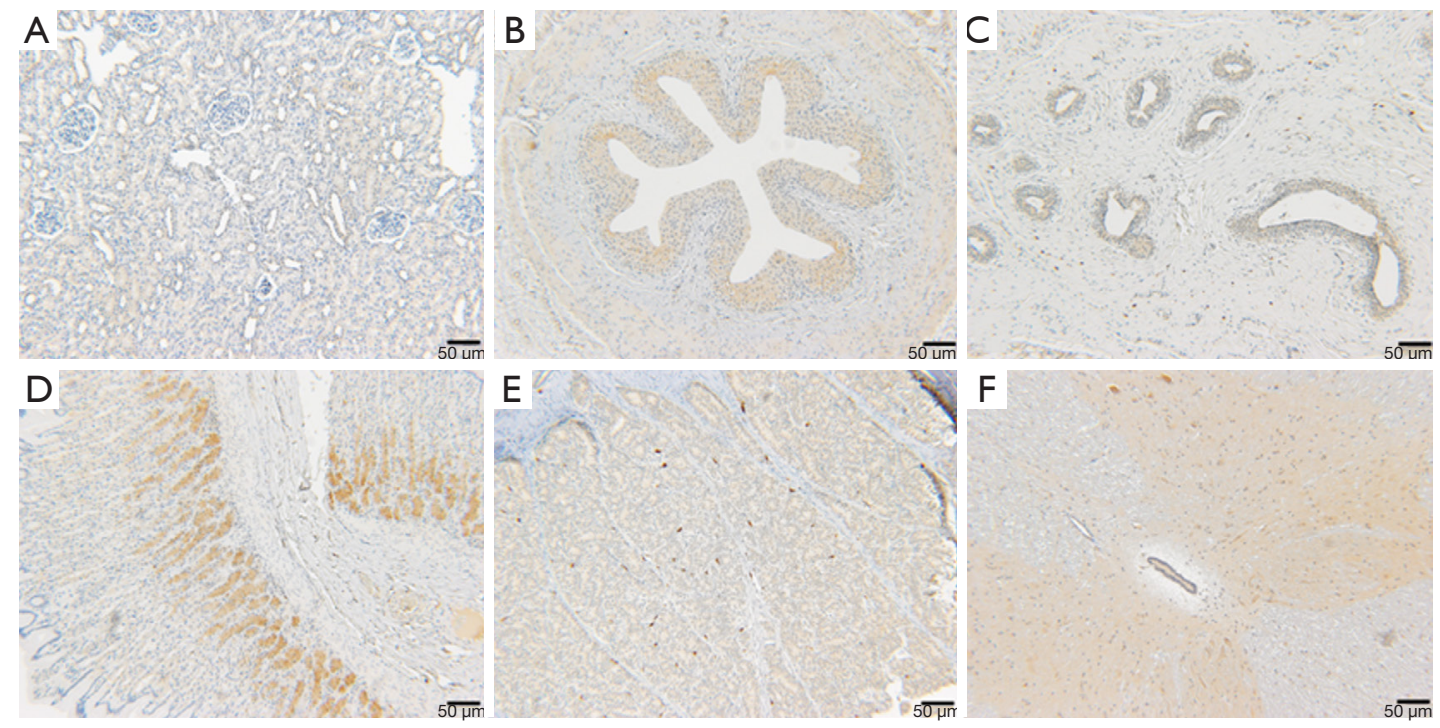

Figure 3 Specific binding of CPGJ701 with normal cynomolgus monkey tissues by IHC. (A) Mild staining (1+) in renal cortical and medullary tubular epithelial cells; (B) moderate staining (2+) in transitional epithelium of ureter; (C) moderate staining $(2+)$ in acinus of mammary gland; (D) moderate staining $(2+)$ in gastric mucosa; (E) mild staining (1+) in epithelial cells of testicular seminiferous tubules and moderate staining $(2+)$ in interstitial mononuclear macrophage; (F) mild staining (1+) in spinal cord neurons and glial cells. IHC, immunohistochemistry.

transitional epithelium of the ureter, the gastric mucosa, the glandular epithelium of the pituitary, thyroid interstitial mononuclear macrophages, the parathyroid gland, the transitional epithelium of the bladder, the cerebellum, the cerebral cortex, the retina, the acinus of the mammary gland, the pancreas, the testicular seminiferous tubules, the endometrium, fallopian tube interstitial mononuclear macrophages and the placenta (Figure 4, Table 3). The staining intensity of the interstitial mononuclear macrophages was higher than that of epithelial cells. Binding of CPGJ701 to the placenta was not found in humans or cynomolgus monkeys, and was only found in Sprague-Dawley rats. The binding of CPGJ701 to the liver, adrenal gland, prostate and skin was observed in humans but not in Sprague-Dawley rats. The differences in the types of tissues that CPGJ701 specifically bound to in SpragueDawley rats compared to humans and cynomolgus monkeys may have been due to differences in the antigen binding sites of humanized anti-HER2 monoclonal antibodies in nonhuman primates and rodents (13).

No specific binding was observed in the liver, the spleen, the adrenal gland, the colon, the lymph nodes, the prostate, the skin, striated muscle, the thymus, the ovaries, bone marrow, the blood vessel endothelium, blood cells or the spinal cord. Bio-IgG and PBS resulted in no positive staining in the 32 normal Sprague-Dawley rat tissues.

\section{Isotype control (Kadcyla) TCR}

The types of human, cynomolgus monkey, and SpragueDawley rat tissues that Kadcyla and CPGJ701 bound to were the same, with only slight differences in the frequency of tissue binding and the intensity of staining (see Table 4).

In conclusion, the binding (i.e., reactivity) of CPGJ701 to normal human, cynomolgus monkey and SpragueDawley rat tissues was identified in the epithelium/ glandular epithelium of the kidney, the ureter, the stomach, the thyroid, the bladder, the retina, the mammary gland, the pancreas, the uterus, and the fallopian tubes. In addition, the cross-reactive epitopes of CPGJ701 were detected in cardiac myocytes, nerve cells, the pituitary, the testes from humans, cynomolgus monkeys and Sprague-Dawley rats and mononuclear macrophages from cynomolgus monkeys and Sprague-Dawley rats. There were some differences in the specific binding of CPGJ701 to human and cynomolgus monkey tissues compared to SpragueDawley rat tissues. For example, CPGJ701 specifically bound to liver, adrenal gland, skin, and spinal cord tissues 

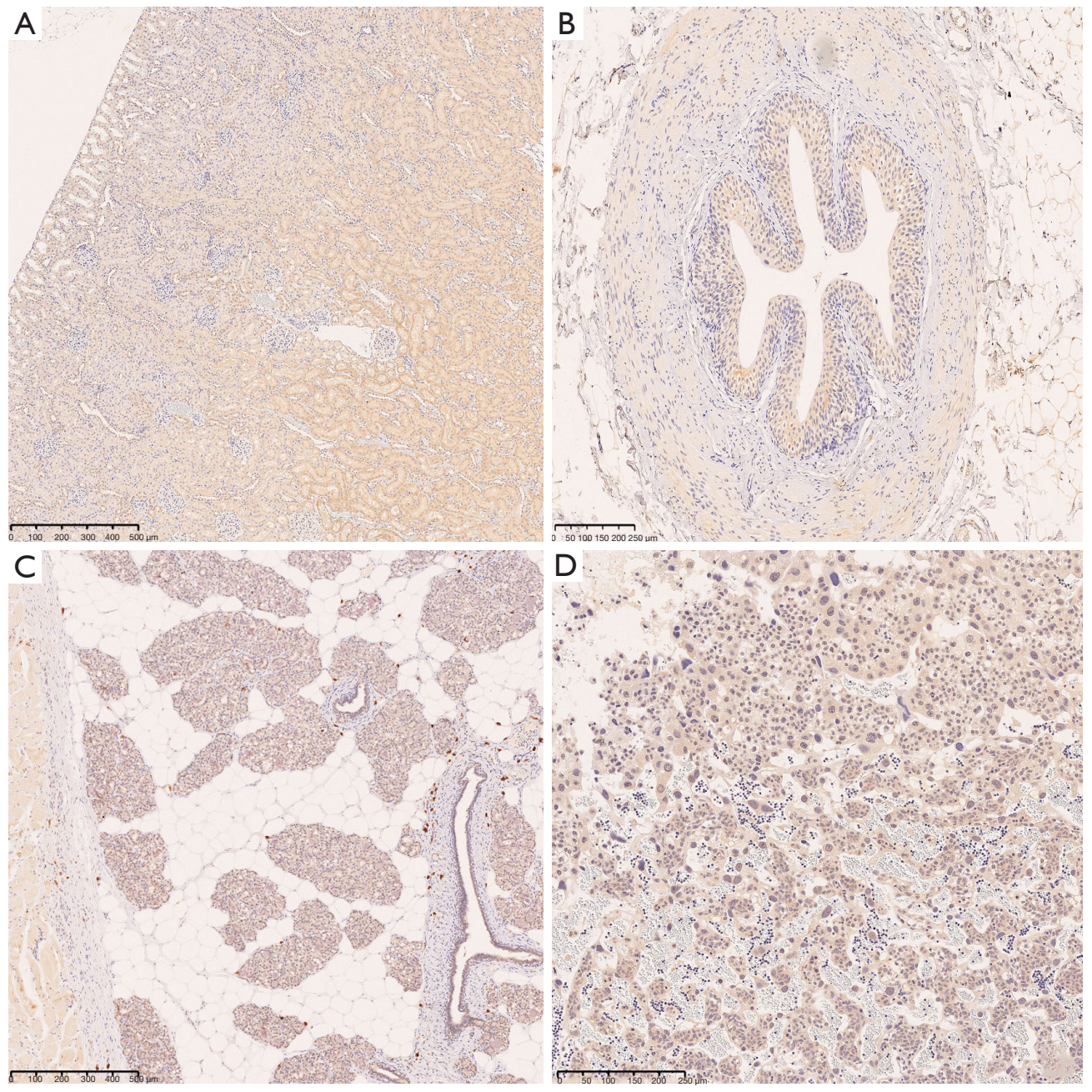

Figure 4 Specific binding of CPGJ701 with normal Sprague-Dawley rat tissues by IHC. (A) Mild staining (1+) in renal cortical and medullary tubular epithelial cells; (B) mild staining (1+) in transitional epithelium of ureter; (C) mild staining (1+) in acinus of mammary gland, and strong staining (3+) in interstitial mononuclear macrophage; (D) mild staining (1+) in placenta. IHC, immunohistochemistry.

from human and cynomolgus monkeys, but no binding was found in the abovementioned tissues from Sprague-Dawley rats. Reactivity and/or cross-reactivity of CPGJ701 was only found in mononuclear macrophages from cynomolgus monkeys and Sprague-Dawley rats, lung tissues from humans and Sprague-Dawley rats, ovarian tissues from cynomolgus monkeys.

\section{Discussion}

In 2013, the US FDA approved trastuzumab emtansine (TDM1; brand name: Kadcyla) for the treatment of HER2positive metastatic breast cancer patients already treated with trastuzumab and paclitaxel (14). It has been reported that the clinical ADRs of T-DM1 include hepatotoxicity, cardiotoxicity, lung toxicity, neurotoxicity, embryo-fetal toxicity, hypersensitivity, and thrombocytopenia (15). Binding of CPGJ701 to human liver, heart, lung, brain and spinal cord tissues in this study explains its clinical ADRs. The cynomolgus monkey tissues to which CPGJ701 bound in the TCR study were consistent with the target organs identified by nonclinical single-dose and repeated-dose toxicity studies, such as liver, kidney, skin, and nervous system tissues. The Sprague-Dawley rat tissues to which CPGJ701 bound to in the TCR study were consistent with the target organs identified by nonclinical toxicity studies, such as lung, kidney, pancreas, thyroid, and reproductive system. 
Table 4 IHC results of Kadcyla binding to tissues in normal humans, cynomolgus monkeys and Sprague-Dawley rats

\begin{tabular}{|c|c|c|c|}
\hline \multirow[b]{2}{*}{32 tissues } & \multicolumn{3}{|c|}{ Bio-Kadcyla $(50 \mu \mathrm{g} / \mathrm{mL})$} \\
\hline & Humans & $\begin{array}{c}\text { Cynomolgus } \\
\text { monkeys }\end{array}$ & $\begin{array}{l}\text { Sprague-Dawley } \\
\text { rats }\end{array}$ \\
\hline Breast cancer & $1+(3 / 3)$ & / & / \\
\hline Heart & $\pm(1 / 3)$ & $1+(1 / 3), \pm(1 / 3)$ & $1+(1 / 3), \pm(2 / 3)$ \\
\hline Lung & $1+(2 / 3)$ & - & $1+(2 / 3)$ \\
\hline Liver & $1+(1 / 3), \pm(1 / 3)$ & $1+(1 / 3), \pm(2 / 3)$ & $\pm(1 / 3)$ \\
\hline Spleen & - & - & - \\
\hline Kidney & $1+(2 / 3),+(1 / 3)$ & $1+(3 / 3)$ & $1+(3 / 3)$ \\
\hline Ureter & $1+(1 / 3)$ & $1+(2 / 3), 2+(1 / 3)$ & $1+(3 / 3)$ \\
\hline Stomach & $1+(3 / 3)$ & $1+(3 / 3)$ & $1+(3 / 3)$ \\
\hline Pituitary & $1+(3 / 3)$ & $1+(2 / 3), \pm(1 / 3)$ & $1+(1 / 3), \pm(1 / 3)$ \\
\hline Adrenal & $1+(2 / 3), 2+(1 / 3)$ & $1+(1 / 3), \pm(1 / 3)$ & - \\
\hline Thyroid & $1+(1 / 3), \pm(1 / 3)$ & $1+(1 / 3)$ & - \\
\hline Parathyroid & ND & $2+(3 / 3)$ & $1+(2 / 3), \pm(1 / 3)$ \\
\hline Bladder & $1+(1 / 3), 2+(2 / 3)$ & $1+(3 / 3)$ & $1+(3 / 3)$ \\
\hline Cerebellum & $1+(1 / 3), \pm(1 / 3)$ & $1+(1 / 3)$ & $1+(2 / 3), \pm(1 / 3)$ \\
\hline Cerebral cortex & $1+(1 / 3)$ & $1+(1 / 3)$ & $1+(2 / 3), \pm(1 / 3)$ \\
\hline Colon & - & $\pm(1 / 3)$ & $\pm(2 / 3)$ \\
\hline Retina & $1+(1 / 1)$ & $1+(1 / 3)$ & $1+(2 / 3)$ \\
\hline Lymph node & - & - & - \\
\hline Breast & $1+(3 / 3)$ & $1+(2 / 3), 2+(1 / 3)$ & $1+(1 / 3)$ \\
\hline Pancreas & $1+(1 / 3)$ & $1+(2 / 3)$ & $1+(3 / 3)$ \\
\hline Prostate & $1+(1 / 3), \pm(1 / 3)$ & $\pm(1 / 3)$ & $\pm(1 / 3)$ \\
\hline Skin & $1+(2 / 3), \pm(1 / 3)$ & $1+(3 / 3)$ & - \\
\hline $\begin{array}{l}\text { Striated } \\
\text { muscle }\end{array}$ & - & - & $\pm(1 / 3)$ \\
\hline Testes & $1+(3 / 3)$ & $1+(2 / 3), \pm(1 / 3)$ & $1+(2 / 3)$ \\
\hline Thymus & - & - & - \\
\hline Uterus & $1+(2 / 3)$ & $\pm(1 / 3)$ & $1+(3 / 3)$ \\
\hline Ovaries & - & $1+(1 / 3)$ & - \\
\hline Fallopian tube & $1+(1 / 3), \pm(1 / 3)$ & $1+(2 / 3), \pm(1 / 3)$ & - \\
\hline Bone marrow & - & - & - \\
\hline Placenta & $\pm(1 / 3)$ & - & $1+(2 / 3), \pm(1 / 3)$ \\
\hline Endothelium & - & - & - \\
\hline Blood cells & - & - & - \\
\hline Spinal cord & $1+(1 / 3), \pm(1 / 3)$ & $1+(3 / 3)$ & - \\
\hline
\end{tabular}

- indicates negative; \pm indicates weak staining; $1+$ indicates mild staining; $2+$ indicates moderate staining; $3+$ indicates strong staining; ND indicates not done; / indicates no; (/) indicates the proportion of different grades of staining. IHC, immunohistochemistry.
No cross-reactivity of CPGJ701 was found in the spleen, thymus or lymph nodes of cynomolgus monkeys or Sprague-Dawley rats, but in nonclinical single-dose and repeated dose toxicity studies, histopathological examination found a decrease in the number of lymphocytes in the white pulp of the spleen, cortex of the thymus and mesenteric lymph nodes, and degeneration and necrosis of lymphocytes in the cortex of the thymus and paracortical area of the mesenteric lymph nodes. Therefore, the immunotoxicity of CPGJ701 to organs may explain the off-target toxicity of DM1. No TCR of CPGJ701 was found in bone marrow from humans, cynomolgus monkeys or Sprague-Dawley rats, but in single-dose and repeated dose toxicity studies, a decrease in the number of bone marrow cells in the sternum and thigh bone was observed by histopathological examination, indicating that the hematopoietic organ toxicity of CPGJ701 may explain the off-target toxicity of DM1. The TCR studies showed that there was specific binding of CPGJ701 to the testis tissues from humans, cynomolgus monkeys and Sprague-Dawley rats, and preclinical toxicity studies have shown that there is a decrease in/degeneration and necrosis of testicular spermatogenic cells in Sprague-Dawley rats, suggesting potential reproductive toxicity in clinical studies.

CPGJ701 was found to bind to spinal cord tissues from humans and cynomolgus monkeys, but not Sprague-Dawley rats. Correspondingly, myelin/axonal degeneration and necrosis of the spinal cord and sciatic nerve of cynomolgus monkeys have been observed in nonclinical toxicity studies of CPGJ701, but such lesions were not seen in SpragueDawley rats. The results of the TCR studies were consistent with the species-specific differences in the toxicity of CPGJ701 in the spinal cord observed in a preclinical toxicity study. It has been reported that the trastuzumab component of T-DM1 binds to nonhuman primate ErbB2 and human HER2 but does not cross-react with the corresponding rodent receptor (c-neu) (16). Therefore, HER2 antigendependent staining of CPGJ701 in human and cynomolgus monkey neurons and glial cells represents species-specific targeted binding.

Trastuzumab has been shown to induce cardiac toxicity in clinical studies. The weak positive binding of CPGJ701 to heart tissues from humans, cynomolgus monkeys and Sprague-Dawley rats observed in the TCR studies suggests a risk of cardiotoxicity. The combination of trastuzumab and anthracyclines may be important for increasing the risk of trastuzumab cardiotoxicity (17), but T-DM1 usually shows cardiac safety and antitumor efficacy (18). The reason 
that neither trastuzumab nor T-DM1 was found to induce cardiotoxicity in nonclinical toxicity studies and safety pharmacology studies may be that they have different safety margins for cardiotoxicity (19-21). Clinically, embryonic toxicity induced by trastuzumab occurs occasionally (22). In this study, CPGJ701 did not bind to placental tissues from humans and cynomolgus monkeys, but bound to placental tissues from Sprague-Dawley rats, indicating that SpragueDawley rats may be a sensitive model for the study of the reproductive toxicity of CPGJ701.

Regarding species selection for nonclinical toxicity studies, considering the similar binding properties of trastuzumab to the nonhuman primate receptor ErbB2 and human HER2 (23), nonhuman primates can be used to evaluate the antibody-dependent toxicity of CPGJ701; additionally, considering the sensitivity of rats to DM1 (24), rats can be used to evaluate the non-antibody-dependent toxicity of CPGJ701. TCR studies can simultaneously assess the specific binding of antibody drugs and possible off-target binding. Nonclinical safety evaluations of T-DM1 and DM1 in rats and cynomolgus monkeys indicated that their toxicity is mainly induced by antigen-independent tubulin inhibition, which is consistent with the mechanism of action and pharmacological activity of DM1 (13). The results of the TCR studies showed that CPGJ701 specifically binds to epithelial cells in many tissues from normal humans, cynomolgus monkeys and SpragueDawley rats because HER2 is widely expressed in epithelial cells (25). The increased mitosis in epithelial cells and axonal degeneration in the spinal cord and of the sciatic nerve observed in nonclinical toxicity studies demonstrate the on-target toxicity of CPGJ701. The immunotoxicity of CPGJ701 is off-target toxicity unrelated to its monoclonal antibody component. Although the types of SpragueDawley rat tissues that were bound were different from the types of human and cynomolgus monkey tissues that were bound, the on-target binding to Sprague-Dawley rat tissues indicated that the Sprague-Dawley rat it one of the animal species that can be used to assess the antibody-dependent toxicity and non-antibody-dependent toxicity of CPGJ701.

In this study, the results of the TCR studies of CPGJ701 in human, cynomolgus monkey and Sprague-Dawley rat tissues confirmed its antibody-dependent toxicity and partial non-antibody-dependent toxicity, which was consistent with the mechanism of action and pharmacological activity of T-DM1: this indicates that TCR studies are an effective method of relating nonclinical toxicity with clinical ADRs in humans and predicting the potential target organs of
ADC toxicity.

\section{Acknowledgments}

The authors would like to thank Sutao Gao and other technicians of Division of Pathology of National Center for Safety Evaluation of Drugs for doing the experiments, Sunshine Guojian Pharmaceutical (Shanghai) Co., Ltd. for providing the test article and related materials for this study. Funding: This work is supported by Project of the 13th National Five-Year Plan for Significant New Drug Creation 'Key Technologies for Non-clinical Safety Evaluation of Innovative Drugs' (No. 2018ZX09201-017).

\section{Footnote}

Conflicts of Interest: The authors have no conflicts of interest to declare.

Ethical Statement: The authors are accountable for all aspects of the work in ensuring that questions related to the accuracy or integrity of any part of the work are appropriately investigated and resolved. The animal experimental studies were approved by the Institutional Animal Care and Use Committee (IACUC) of National Center for Safety Evaluation of Drugs (NCSED) (No. IACUC-2013-041, IACUC-2015-070).

Open Access Statement: This is an Open Access article distributed in accordance with the Creative Commons Attribution-NonCommercial-NoDerivs 4.0 International License (CC BY-NC-ND 4.0), which permits the noncommercial replication and distribution of the article with the strict proviso that no changes or edits are made and the original work is properly cited (including links to both the formal publication through the relevant DOI and the license). See: https://creativecommons.org/licenses/by-nc-nd/4.0/.

\section{References}

1. Beck A, Goetsch L, Dumontet C, et al. Strategies and challenges for the next generation of antibody-drug conjugates. Nat Rev Drug Discov 2017;16:315-37.

2. Lewis Phillips GD, Li G, Dugger DL, et al. Targeting HER2-positive breast cancer with trastuzumab-DM1, an antibody-cytotoxic drug conjugate. Cancer Res 2008;68:9280-90.

3. Barok M, Joensuu H, Isola J. Trastuzumab emtansine: 
mechanisms of action and drug resistance. Breast Cancer Res 2014;16:209.

4. Xu Z, Guo D, Jiang Z, et al. Novel HER2-targeting antibody-drug conjugates of trastuzumab beyond T-DM1 in breast cancer: trastuzumab deruxtecan(DS-8201a) and (Vic-)trastuzumab duocarmazine (SYD985). Eur J Med Chem 2019;183:111682.

5. Masters JC, Nickens DJ, Xuan D, et al. Clinical toxicity of antibody drug conjugates: a meta-analysis of payloads. Invest New Drugs 2018;36:121-35.

6. Coats S, Williams M, Kebble B, et al. Antibody-drug conjugates: future directions in clinical and translational strategies to improve the therapeutic index. Clin Cancer Res 2019;25:5441-8.

7. Hinrichs MJ, Dixit R. Antibody drug conjugates: nonclinical safety considerations. AAPS J 2015;17:1055-64.

8. Huang Y, Huo Y, Wang X, et al. Strategy and case studies in preclinical safety evaluation of new antibody drugs. Drug Evaluation Research 2018;41:35-40.

9. Hong M, Zhao XP, Ma J. Preclinical safety evaluation strategy for antibody drug conjugates. Chin J Pharmacol Toxicol 2016;30:7-12.

10. Yu SS, Wang HX, Hu XM, et al. Application of tissue crossreactivity test in non-clinical safety evaluation and case studies. Chinese Journal of NewDrugs 2016;25:634-38.

11. ICH. Preclinical safety evaluation of biotechnologyderived pharmaceuticals S6(R1) [EB/OL]. (1997-07-16) [2015-11-21]. Available online: https://admin.ich.org/sites/ default/files/inline-files/S6_R1_Guideline.pdf

12. FDA. Points to consider in the manufacture and testing of monoclonal antibody products for human use [EBOL]. (1997-02-28) [2015-11-21]. Available online: https://www. fda.gov/media/76798/download

13. Poon KA, Flagella K, Beyer J, et al. Preclinical safety profile of trastuzumab emtansine (T-DM1): mechanism of action of its cytotoxic component retained with improved tolerability. Toxicol Appl Pharmacol 2013;273:298-313.

14. Kadcyla [package insert]. South San Francisco: Genentech
Inc., 2013.

15. Krop I, Winer EP. Trastuzumab emtansine: a novel antibody-drug conjugate for HER2-positive breast cancer. Clin Cancer Res 2014;20:15-20.

16. Herceptin [package insert]. South San Francisco: Genentech Inc., 2010.

17. Hamirani Y, Fanous I, Kramer CM, et al. Anthracyclineand trastuzumab-induced cardiotoxicity: a retrospective study. Med Oncol 2016;33:82.

18. Yardley DA, Krop IE, LoRusso PM, et al. Trastuzumab emtansine (T-DM1) in patients with HER2-positive metastatic breast cancer previously treated with chemotherapy and 2 or more HER2-targeted agents: results from the T-PAS expanded access study. Cancer J 2015;21:357-64.

19. Bregni G, Galli G, Gevorgyan A, et al. Trastuzumab cardiac toxicity: a problem we put our heart into. Tumori 2016;102:1-5.

20. Lambertini M, Pondé NF, Solinas C, et al. Adjuvant trastuzumab: a 10-year overview of its benefit. Expert Rev Anticancer Ther 2017;17:61-74.

21. De Lorenzo C, Paciello R, Riccio G, et al. Cardiotoxic effects of the novel approved anti-ErbB2 agents and reverse cardioprotective effects of ranolazine. Onco Targets Ther 2018;11:2241-50.

22. Herceptin European Summary of Product Characteristics [EB/OL]. [2013-04-25]. Available online: http://www. ema.europa.eu/docs/en_GB/document_library/EPARProduct_Information/human/000278/WC500074922.pdf

23. Danese MD, Lalla D, Brammer M, et al. Estimating recurrences prevented from using trastuzumab in HER-2/ neu-positive adjuvant breast cancer in the United States. Cancer 2010;116:5575-83.

24. Issell BF, Crooke ST. Maytansine. Cancer Treat Rev 1978;5,199-207.

25. Press MF, Cordon-Cardo C, Slamon DJ. Expression of the HER-2/neu protooncogene in normal human adult and fetal tissues. Oncogene 1990;5:953-62.
Cite this article as: Qu Z, Lyu J, Liu Y, Wang X, Lin Z, Yang Y, Zhang D, Geng X, Li B. Tissue cross-reactivity studies of CPGJ701 in humans, cynomolgus monkeys and SpragueDawley rats and correlation analysis with in vivo toxicity. Ann Transl Med 2020;8(6):325. doi: 10.21037/atm.2020.02.106 